\title{
Comparing individual and spatial influences on foraging behaviour in Antarctic fur seals Arctocephalus gazella
}

\author{
Iain J. Staniland ${ }^{1, *}$, Keith Reid ${ }^{1}$, Ian L. Boyd ${ }^{2}$ \\ ${ }^{1}$ British Antarctic Survey, Natural Environmental Research Council, High Cross, Madingley Road, Cambridge CB3 0ET, UK \\ ${ }^{2}$ Sea Mammal Research Unit, Gatty Marine Laboratory, University of St Andrews, St Andrews KY16 0HS, UK
}

\begin{abstract}
We investigated intra-specific and geographic variation in the behaviour of female Antarctic fur seals Arctocephalus gazella by serially sampling 11 individuals throughout their breeding season using satellite tracking, time-depth recorders and radio transmitters. There was significant variation between individuals in trip durations and the maximum distance reached from the breeding beach, but not in the direction of travel. We recognised 4 categories of trip duration, depending on the location of foraging: long deep-location, long intermediate-location, short intermediate-location and short shallow-location, based on the maximum distance reached from the breeding beach and the mean depth of water where diving occurred. Trip category accounted for a greater amount of the variation between trips than the identity of the seal. Seals on long deeplocation trips spent proportionally less time diving, had a lower dive rate, and dived to shallower depths for shorter durations with less bottom time than seals on short shallow-location trips. There was no significant difference in the total number of dives within trips between trip categories or between individual seals. There was also no significant difference in either the mean size of krill taken by individual seals or the incidence of fishes in their diet. These data suggest there is a strong individual component to where a seal forages especially in terms of the distance it travels from the breeding beach. However, we suggest that it is where an individual forages, not who that individual is, that determines how it will behave in terms of its diving. While individual seals may exploit areas of previous feeding success, their diving behaviour within these areas is likely to be determined by the spatial and temporal distribution of the prey within them.
\end{abstract}

KEY WORDS: Antarctic fur seal - Arctocephalus gazella - Individual variation - Foraging - Diet · Geographic variation · Diving behaviour $\cdot$ South Georgia

Resale or republication not permitted without written consent of the publisher

\section{INTRODUCTION}

Population ecology has traditionally overlooked individual differences and treated populations as homogeneous units. To understand the dynamic behaviour of a population we must also understand the causes of the differences in the behaviour of individuals (Lomnicki 1980, 1988). Underpinning studies of populations with an understanding of individual variation will increase the predictive power of population ecology (Sutherland 1997).
Individual differences in foraging behaviour have been recorded in a wide range of animal taxa from invertebrates (Pernal \& Currie 2001) to mammals (Fedriani \& Kohn 2001). These differences can occur through a number of mechanisms including different prey capture or harvesting tactics (Bence 1986), morphological differences (i.e. age, size, gender; Werner \& Gilliam 1984), intra-specific competition (Milinski 1982), experience (Pernal \& Currie 2001) and habitat selection (Heithaus et al. 2002). These mechanisms often interact (Whitfield 1990) making it difficult to 
determine the underlying force driving any apparent variation. For example, in striped surfperch Embiotoca lateralis, dietary specialisation is a passive consequence of patch selection rather than a result of active prey choice (Holbrook \& Schmitt 1992), whereas the habitat choice of oystercatchers Haematopus ostralegus is determined by both their method of feeding and their age (Gosscustard \& Sutherland 1984).

Previous studies have shown there is a high level of variation in the foraging behaviour of lactating female Antarctic fur seals Arctocephalus gazella at South Georgia (Boyd 1999). To provision their pups, females act as central place foragers, undertaking trips to sea which can vary in duration between 2 and 8 d (McCafferty et al. 1998). However, irrespective of their trip durations, mothers appear to be able to maintain the same average rate of delivery of energy to their offspring under most environmental conditions (Arnould \& Boyd 1995). This may be because foraging in these predators appears to be optimised to maintain the maximum rate of delivery of energy to the offspring (Boyd et al. 1997). Staniland \& Boyd (2003) showed that there was a strong positive correlation between trip duration and the distance the seal travelled from the breeding beach. Depending on their trip duration, seals exploited either continental shelf or oceanic environments, and their diving behaviour differed between the two. Seals on short duration trips to shelf waters had both a higher dive rate (vertical distance dived $\mathrm{h}^{-1}$ ) and a higher incidence of deeper daytime diving than those foraging in oceanic waters. Dives by fur seals are regarded as foraging events and differences in diving behaviour are thought to reflect differences in their prey. Staniland et al. (unpubl.) showed a difference in the fish consumption between animals returning from trips of long or short durations. This suggests that an increased consumption of energy-rich fish prey in oceanic waters could offset the increased costs of travelling for both a longer duration of foraging trip and a greater distance travelled from the colony.

The objective of this study was to test the hypothesis that these differences in the foraging behaviour of individuals are determined by intrinsic differences in their foraging performance rather than by the environment in which they are foraging. To do this, we carried out remote recording of individuals during their foraging in different environments. The specific aims were to address the questions (1) Do individuals display preferences in their foraging locations? (2) Is individual variation or foraging location driving observed differences in diving behaviour? (3) Is there any evidence of differences in the diet between individuals irrespective of the foraging location?

\section{MATERIALS AND METHODS}

Foraging trip duration. We studied 11 female Antarctic fur seals from Freshwater beach, Bird Island, South Georgia $\left(54^{\circ} 00^{\prime} \mathrm{S}, 38^{\circ} 02^{\prime} \mathrm{W}\right)$, throughout their breeding season in the Austral summer of 1998/99. These females were caught soon after they had given birth to their pups and a small $(6 \times 2 \times 2 \mathrm{~cm},<30 \mathrm{~g})$ radio-transmitter (Sirtrack) was glued to their fur in the mid-dorsal region (Boyd et al. 1998). The foraging trip duration was measured using a scanning radioreceiver (Televilt International) that automatically recorded the presence of these seals at the breeding colony. The foraging trip durations were then compared for each seal within the study using a Model II analysis of variance (ANOVA: Sokal \& Rohlf 1995).

Foraging location. Each female was tracked at sea on a number of foraging trips throughout the season using the ARGOS satellite tracking system (CLS ARGOS). Platform transmitter terminals, PTT, cast a$400,13 \times 4 \times 2 \mathrm{~cm}, 200 \mathrm{~g}$ (Telonics ST10), were attached by plastic cable ties to a strip of webbing glued to the fur of each study seal, centrally located in the mid-dorsal region between the scapulae. Using this indirect method of attachment allowed the PTT to be deployed and removed at different times with minimal interference to the study individual. PTT deployments were spread throughout the breeding season so that each individual was represented in all stages of lactation.

Foraging locations were calculated from the satellite uplinks after filtering to remove potentially unreliable records. We used the ARGOS system of classification of position fixes as a guide to accuracy. Fixes calculated from less than 3 uplinks of the PTT (graded by ARGOS A B or Z) were discarded. Argos Class 0 locations (mean accuracy 3.7 km; Boyd et al. 1998) were rejected if the average speed needed to reach them from the previous location exceeded $2 \mathrm{~m} \mathrm{~s}^{-1}$ based on average swimming speeds reported in Boyd (1996). The remaining Class 0 locations were also rejected if another higher quality (mean accuracy $<1.5 \mathrm{~km}$ ) position-fix occurred within $1 \mathrm{~h}$. All Argos Class 1, 2 and 3 locations were accepted. The distance to the maximum point reached from the breeding colony was calculated for each satellite tracked trip and the compass bearing of this position from the breeding beach was determined.

The variation in these 2 indices of the seals' foraging locations was investigated using a Model II ANOVA (Sokal \& Rohlf 1995). Circular statistics were not used to analyse the angle data as the spread of values was very small (within 0.68 radians) and linear analysis was adequate (Batschelet 1981).

Pup mass. Pups were weighed as regularly as possible before weaning (82 to $114 \mathrm{~d}$ of age) while the 
mother was at sea on a foraging trip. The mean masses of pups were regressed against mean trip duration. Due to the difficulty in locating individuals within the widespread colony, 3 pups were not represented in this analysis.

Diving behaviour. The diving behaviour of the study individuals was measured using time-depth recorders TDR $9.5 \times 2.5 \times 2.5 \mathrm{~cm}, 50 \mathrm{~g}$ (Mk VII, Wildlife Computers), which were attached to the webbing posterior to the satellite tag. The TDRs were programmed to measure depth to a resolution of $1 \mathrm{~m}$ every $2 \mathrm{~s}$ for the duration of the foraging trip. The dive record was retrieved from the memory of the TDR after its recovery from the seal. Each record was analysed using purposebuilt software that allowed correction of drift in the zero depth reading. To avoid inaccuracies in determining when seals were at or near the surface, only excursions to $>2 \mathrm{~m}$ were considered to be dives. The TDR record from each seal was combined with the relevant satellite position fixes to give an approximate location for each dive. When the time recorded for a dive fell between the times of 2 satellite position fixes, the location was interpolated based upon the time of the dive relative to the 2 fixes and assuming that the seal swam at a constant speed between the 2 positions (Boyd et al. 1998).

The depth of water at the estimated location of each dive was approximated by selecting the nearest known depth value from an unpublished British Antarctic Survey bathymetric data set on a longitude latitude grid. We used 2 variables to categorise trips: (1) mean depth of water in which dives took place, and (2) the maximum distance reached from Bird Island (PROC FASTCLUS: SAS Institute). The categorisation used a disjoint cluster analysis on the basis of Euclidean distances; all distances between trips within a category were less than the distances between trips in different categories. The relationship between the number of trip categories (or clusters) observed and the proportion of variance resolved by them approached an asymptote (Fig. 1). This showed that classifying the trips into 4 categories accounted for $88 \%$ of the variation. Since adding a fifth category explained only a further $2 \%$ of the variation in the data, we used 4 categories in further analyses.

Variation in diving behaviour was analysed using ANOVA, with the identity of individual seals and trip category entered as factors, and dive rate, percentage time spent diving, total number of dives, mean dive depth, mean dive duration and mean bottom time entered as variables. The dive rate $\left(\mathrm{m} \mathrm{h}^{-1}\right)$ was calculated from the mean vertical distance the seal travelled per hour of the trip. Bottom time was calculated as the time of a dive between when the seal stopped descending and when it began to ascend. Descent and ascent transitions were calculated as when the instantaneous rate of vertical movement decreased below the mean rate, measured between the surface and the maximum depth (Boyd et al. 1995). The distributions of dive depth and duration within trips were highly skewed and were therefore log-transformed before means were calculated. Bottom times were also normalised using a square-root transformation.

Diet. After each seal returned to the colony it was given an enema, by introducing approximately 11 of water at body temperature into the colon through a flexible plastic tube. When this water was expelled naturally by the seal, faecal material in the colon was flushed out. This was collected in a shallow plastic tray held beneath the anus and rear flippers (Staniland et al. 2003). Faecal material collected from the tray was processed according to the methods described in Reid (1995). Each sample was broken down in a solution of $1 \%$ detergent and gently agitated so that prey remains could be separated. Material that was in suspension (e.g. krill carapaces) was poured into a sorting tray $(35 \times 45 \mathrm{~cm})$ and examined. The dense residue remaining was examined under a binocular microscope and prey remains such as fish otoliths, bones and eye lenses were picked out. Otoliths were identified to species level where possible using an identification key (Reid 1996). Because of difficulty in distinguishing some eroded nototheniid otoliths, they were described as a single group: Lepidonoitothen larseni aggregation. Up to 50 krill carapaces were sub-sampled from each enema when possible, and the original lengths were back-calculated from the removed carapace lengths using the techniques and equations described in Reid \& Measures (1998).

The sizes of krill taken by each individual seal were compared using a Model II ANOVA (Sokal \& Rohlf 1995) with mean carapace length in each enema as the sampling unit.

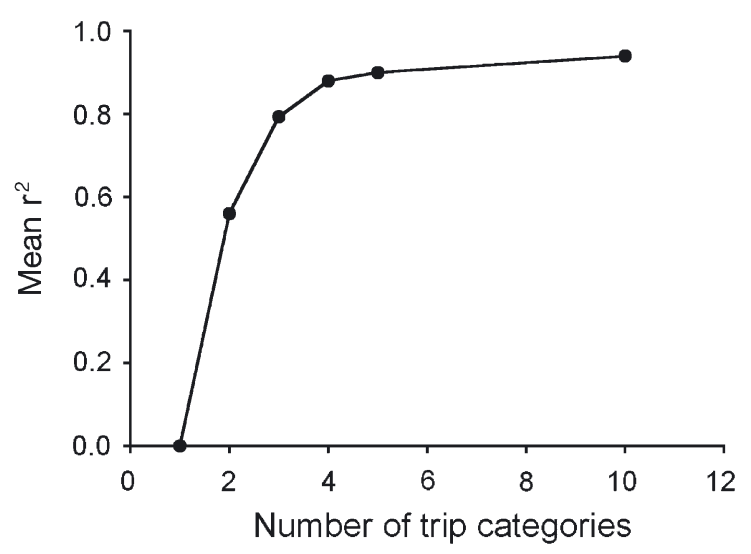

Fig. 1. Arctocephalus gazella. Variation (mean $\mathrm{r}^{2}$ ) in maximum distance travelled from Bird Island and mean depth of water in which seals dived, as a function of different numbers of trip categories (clusters) observed 
The incidence of fishes was calculated as the number of enemas containing traces of fishes divided by the total number of enemas from each seal. These were then compared using a G-test of independence (Sokal \& Rohlf 1995). The median numbers of otoliths per enema were compared between individual seals using a Kruskal-Wallis test.

Post hoc pairwise comparisons between means were made for significant factors using the Tukey-Kramer method based on the Studentized range to control maximum experimentwise error rate (PROC GLM, SAS Institute). The amount of variation explained by the factors in the ANOVA models was calculated with PROC VARCOMP (SAS Institute) using the Type 1 method.

\section{RESULTS}

\section{Foraging trip duration}

Details of measurements made on each seal are shown in Table 1. The results of the Model II ANOVA comparing the variation in trip duration showed that there were significant differences between seals
(ANOVA: $\left.F_{10,111}=3.898, \mathrm{p}<0.001\right)$. Examining the components of variation showed that $20.7 \%$ was accounted for by the identity of the seal. The comparison of means showed that Seals w2363 and w5585 both had on average significantly shorter trip durations than Seals w1717 and w1753 (Table 1). A regression of mean trip duration against female age showed a significant positive relationship (duration $=5.49 \times$ age $+75.73 ; F_{1,9}$ $=19.07, \mathrm{r}^{2}=0.74, \mathrm{p}=0.002$ ). There was no significant relationship between pup mass and the mean trip duration of the mother (regression: $F_{2,5}=2.067, \mathrm{p}=0.2217$ ).

\section{Foraging location}

The diving-density plots in Fig. 2 show that the point of maximum distance from the breeding colony was a good proxy for foraging location and that there were differences in the foraging ranges of individual seals. The plots show that some seals were foraging in oceanic waters (>1000 $\mathrm{m}$ in depth) far from the breeding beach $(>100 \mathrm{~km})$ whereas others foraged in shallower shelf waters. In all cases the seals restricted their range to an area northwest of the breeding colony with virtually no southerly or easterly component to their locations.

Table 1. Arctocephalus gazella. Details of female Antarctic females used in study, and numbers of trips by each seal that fell into 1 of the 4 trip-category clusters (long, short: long and short distance, respectively; deep, interm, shallow: deep, intermediate and shallow locations, respectively). $f$ : weighing frequency of pups; f: female; $\mathrm{m}$ : male; PTT: platform transmitter terminal

\begin{tabular}{|c|c|c|c|c|c|c|c|c|c|c|c|c|}
\hline Tag no.: & w1717 & w1753 & w2301 & w2317 & w2363 & w3913 & w5341 & w5342 & w5511 & w5585 & w5753 & Total \\
\hline \multicolumn{13}{|l|}{ Female } \\
\hline Mass (kg) & 39.5 & 45.0 & 43.0 & 44.5 & 46.0 & 47.0 & 39.5 & 32.0 & 44.0 & 40.0 & 38.0 & \\
\hline Length (cm) & 121 & 134 & 141 & 130 & 131 & 140 & 140 & 121 & 142 & 132 & 138 & \\
\hline Age & 16 & 20 & 17 & 14 & 8 & 12 & 10 & 9 & 10 & 9 & - & \\
\hline \multicolumn{13}{|l|}{ Pup } \\
\hline Sex & $\mathrm{m}$ & $\mathrm{f}$ & $\mathrm{f}$ & $\mathrm{m}$ & $\mathrm{m}$ & $\mathrm{m}$ & $\mathrm{m}$ & $\mathrm{f}$ & $\mathrm{m}$ & $\mathrm{m}$ & $\mathrm{f}$ & \\
\hline Mass (kg) & 11.1 & 10.2 & 7.8 & - & 14.1 & 12.2 & 11.4 & - & 10.4 & 10.3 & - & \\
\hline$f(\mathrm{SD})$ & $4(0.21)$ & $2(1.06)$ & $2(0.52)$ & - & $2(0.57)$ & $3(0.65)$ & $2(1.98)$ & - & $2(0.21)$ & $1(-)$ & - & \\
\hline \multicolumn{13}{|l|}{ Trip duration (h) } \\
\hline $\mathrm{n}$ & 11 & 9 & 9 & 7 & 13 & 15 & 10 & 11 & 12 & 14 & 11 & 122 \\
\hline Mean & 175.5 & 178.1 & 163.2 & 168.9 & 114.4 & 129.2 & 157.1 & 125.7 & 126.1 & 117.4 & 140.3 & \\
\hline SD & 30.0 & 47.1 & 36.4 & 41.3 & 24.1 & 51.2 & 49.8 & 49.2 & 30.6 & 39.8 & 29.6 & \\
\hline \multicolumn{13}{|l|}{ PTT deployments } \\
\hline $\begin{array}{l}\mathrm{n} \\
\text { Distance }(\mathrm{km})\end{array}$ & 4 & 4 & 5 & 4 & 5 & 5 & 5 & 4 & 5 & 5 & 5 & 51 \\
\hline Mean & 162 & 150 & 96 & 133 & 65 & 87 & 113 & 78 & 98 & 69 & 55 & \\
\hline $\mathrm{SD}$ & 31 & 48 & 25 & 58 & 11 & 47 & 45 & 21 & 25 & 14 & 9 & \\
\hline \multicolumn{13}{|l|}{ Angle (radians) } \\
\hline Mean & 1.27 & 1.26 & 1.20 & 1.17 & 1.32 & 1.01 & 1.25 & 1.34 & 1.39 & 1.34 & 0.71 & \\
\hline SD & 0.04 & 0.13 & 0.18 & 0.10 & 0.10 & 0.39 & 0.26 & 0.15 & 0.12 & 0.06 & 0.69 & \\
\hline \multicolumn{13}{|l|}{ Trip category } \\
\hline Long deep & 1 & 2 & 1 & 1 & - & - & - & - & - & - & 1 & 6 \\
\hline Long interm & 1 & - & 1 & 1 & - & 1 & 1 & 1 & - & - & - & 6 \\
\hline Short interm & - & 1 & 1 & 1 & 2 & 2 & 2 & 1 & 1 & 1 & - & 12 \\
\hline Short shallow & - & 1 & 1 & - & 2 & 1 & 1 & 1 & 2 & 3 & 3 & 15 \\
\hline
\end{tabular}



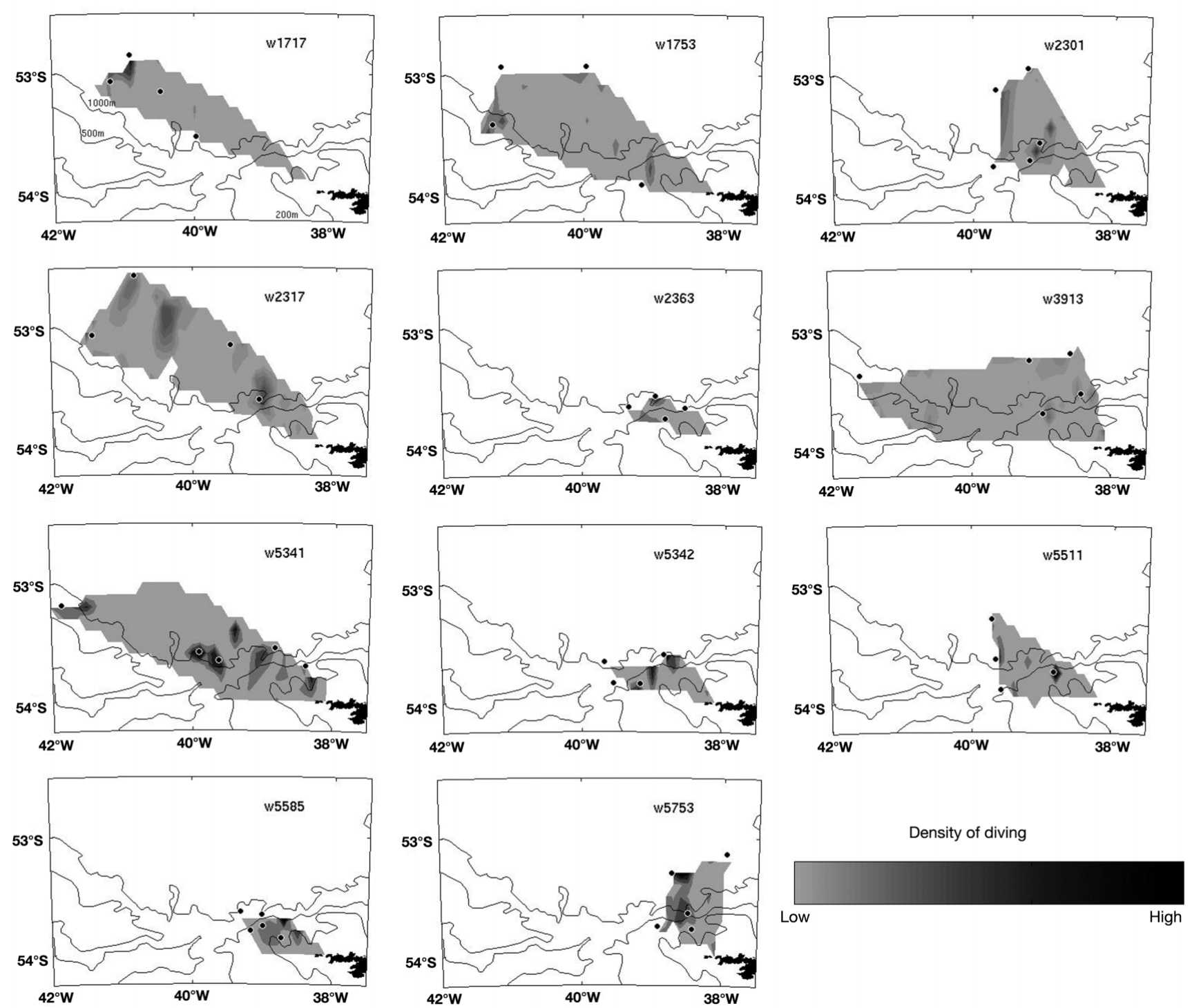

Fig. 2. Arctocephalus gazella. Diving-density plots for each seal studied combined over all trips that had concurrent PTT (platform transmitter terminals) and TDR (time-depth recorders) deployments at northern end of South Georgia, showing 200, 500 and 1000 m depth contours. Plots were constructed from contour plots of 7 contours with linear spline interpolation. (•) Points of maximum distance reached from the breeding beach on respective trips

The maximum distance (Table 2) was not normally distributed, as the variance was positively correlated with the mean (Pearson correlation coefficient $=0.635$, $\mathrm{p}=0.03$ ) and we therefore used a logarithmic transformation on these data. When comparing the transformed values there was a strong significant difference between the seals in terms of their mean maximum distance reached (ANOVA: $F_{10,38}=3.583, p=0.002$ ). Examining the components of variation showed that $36.7 \%$ was accounted for by the identity of the seal. The comparison of group means showed that Seals w2363, w5753 and w5585 had significantly shorter trip distances than w1717 and w1753 (Table 1), and w5753 was also significantly different from w2317.

The angle of travel from the colony (Table 1) was not normally distributed, as the variance was negatively correlated with the mean (Pearson correlation coefficient $=-0.933, \mathrm{p}<0.01$ ), and we therefore used a logarithmic transformation on these data. Using this square-root-transformed compass-bearing from the colony, there was no significant difference between individuals (ANOVA: $F_{10,38}=1.94, p=0.069$ ). The analysis of group means showed that the 2 seals with the greatest difference were w5753 and w5342 (Table 1). 
Table 2. Arctocephalus gazella. Comparison of diving and trip parameters between trip categories and individual seals. Values are means (SE)

\begin{tabular}{|lccccccc|}
\hline Trip category & $\begin{array}{c}\text { Max. distance } \\
(\mathrm{km})\end{array}$ & $\begin{array}{c}\text { Mean water } \\
\text { depth }(\mathrm{m})\end{array}$ & $\begin{array}{c}\text { Trip duration } \\
(\mathrm{h})\end{array}$ & $\begin{array}{c}\text { Total no. } \\
\text { of dives }\end{array}$ & $\begin{array}{c}\text { \% time } \\
\text { diving }\end{array}$ & $\begin{array}{c}\text { Dive rate } \\
\left(\mathrm{m} \mathrm{h}^{-1}\right)\end{array}$ & $\begin{array}{c}\text { Travel } \\
(\mathrm{h})\end{array}$ \\
\hline Long deep-location & $143(21)$ & $2869(81)$ & $162.84(7.2)$ & $2767(357)$ & $19.0(1.19)$ & $310.45(23.95)$ & $6.4(1.5)$ \\
Long intermediate-location & $127(24)$ & $2078(105)$ & $191.28(22.1)$ & $2306(349)$ & $22.2(1.91)$ & $375.84(32.5)$ & $6.8(0.8)$ \\
Short intermediate-location & $85(11)$ & $1123(41)$ & $157.44(17.5)$ & $2817(291)$ & $27.6(1.43)$ & $426.44(24.34)$ & $7.5(0.9)$ \\
Short shallow-location & $51(4)$ & $360(82)$ & $115.68(6.5)$ & $1944(111)$ & $31.7(1.05)$ & $500.52(26.97)$ & $7.2(0.8)$ \\
\hline
\end{tabular}
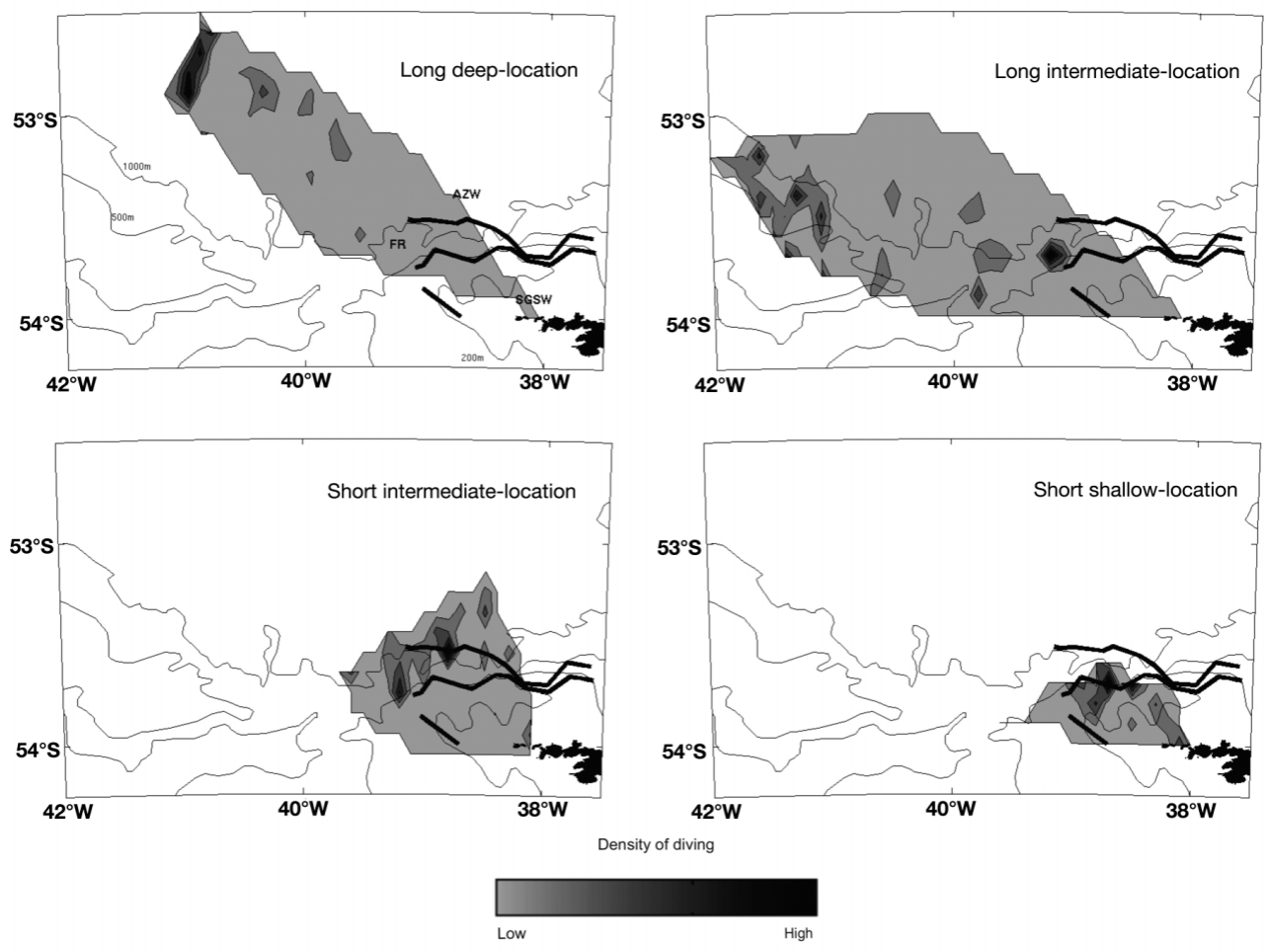

Fig. 3. Arctocephalus gazella. Diving-density plots for trip category suggested by cluster analysis using maximum distance and mean depth of water dived in the 4 trip categories at northern end of South Georgia; 200, 500 and $1000 \mathrm{~m}$ depth contours are shown. Plots were constructed from contour plots of 7 contours with linear spline interpolation. Thick black lines: frontal positions identified by Brandon et al. (2000) (AZW: Antarctic Zone Water; SGSW: South Georgia Shelf Water; FR: Frontal Region)

The 4 trip categories suggested by clustering the data were termed long deep-location, long intermediate-location, short intermediate-location, and short shallow-location based on the mean characteristics of trips within them (Table 2, Fig. 3). The number of trips by each seal contained within each of the 4 clusters is shown in Table 1. All seals were represented in at least 2 categories and 1 seal (w2301) was represented in all 4 . The 2 categories representing short distance trips were the most common, containing over twice as many trips as the longer categories. Due to failure of some TDRs, not all foraging trips with PPT deployments could be categorised.

\section{Diving behaviour}

There was no significant variation in the total number of dives on a trip in relation to individual seal and trip category (ANOVA: $F_{13,25}=1.448, p=0.2063$ ), showing that the number of dives per trip was independent of the location of trip.

There was a significant difference in percentage of time on a trip spent diving in relation to trip category and individual seal (ANOVA: $F_{13,25}=7.184, \mathrm{p}<0.001$ ). Trip category accounted for $59 \%$ of the variation $\left(F_{3,35}=\right.$ $12.44, \mathrm{p}<0.001)$ compared to $14 \%\left(F_{10,28}=2.711, \mathrm{p}=\right.$ 0.02 ) accounted for by individual. When comparing 
group means, no significant differences were found between individual seals, but those on long deep-location and long intermediate-location trips spent a significantly lower proportion of their time diving than those on short intermediate-location and short shallow-location trips.

Dive rate was also significantly different between individuals and trip categories (ANOVA: $F_{13,25}=6.271$, $\mathrm{p}<$ 0.001). Trip category accounted for $40.9 \%$ of variation $\left(F_{3,35}=8.066, \mathrm{p}<0.001\right)$ compared to $23.2 \%$ for individual $\operatorname{seal}\left(F_{10,28}=3.627, \mathrm{p}=0.004\right)$. Comparing the mean dive rates for individuals showed that w2317 $\left(289.3 \mathrm{~m} \mathrm{~h}^{-1}\right)$ had a significantly lower rate than w2363 (485.7 $\left.\mathrm{m} \mathrm{h}^{-1}\right)$. Long deep-location trips had significantly lower dive rates than short intermediate-location and short shallow-location trips. Long intermediate-location trips also had a significantly lower dive rate than short shallow-location trips.

There was a significant difference in dive depths between trips in relation to category and individual seal (ANOVA: $F_{13,25}=2.921, \mathrm{p}=0.01$ ). Partitioning the variance showed that $26.7 \%$ of the variation could be accounted for by trip category $\left(F_{3,35}=4.803, \mathrm{p}=0.009\right)$ and $18 \%$ by individual $\left(F_{10,28}=2.083, \mathrm{p}=0.066\right)$, suggesting that the reason for the difference in the dive depths between individuals was because of location rather than the individual. Seals on long deep-location trips dived on average to shallower depths than those on short shallow trips (Fig. 4).

Using the mean dive duration of each trip as the response variable produced results similar to those of dive depth (ANOVA: $F_{13,25}=2.862, \mathrm{p}=0.01$ ). Trip category accounted for $26.1 \%$ of the variation $\left(F_{3,35}=\right.$ $4.535, \mathrm{p}=0.011)$ compared to $17.9 \%$ by individual $\left(F_{10,28}=2.061, \mathrm{p}=0.069\right)$. Dives within long deep-location trips were on average shorter in duration than dives within short shallow-location trips (Fig. 5).

There was a significant difference in the mean bottom times between trips (ANOVA: $F_{13,25}=2.649, \mathrm{p}=$ $0.017)$. Only the trip category accounted for a significant amount of variation $24.8 \%\left(F_{3,35}=4.162, \mathrm{p}=\right.$ 0.016). Dives within long deep-location trips had on average shorter bottom times than dives within short shallow-location trips (Fig. 6).

All trip categories were dominated by dives in the top $10 \mathrm{~m}$ of the water column, with durations of $<10 \mathrm{~s}$ and with very short bottom times (Figs. 4 to 6). However, short shallow trips and, to a lesser extent, long intermediate-location and short intermediate-location trips had a secondary peak of dives to about $30 \mathrm{~m}$ depth lasting about $90 \mathrm{~s}$ and with bottom times of about $50 \mathrm{~s}$.

\section{Diet}

There was no significant difference in the length of krill sampled from individual seals (ANOVA: $F_{10,102}=$
$0.48, \mathrm{p}<0.90$ ). The incidence of fishes was also not significantly different between seals (G-test of independence: $G_{\mathrm{adj}}=9.288, \mathrm{df}=10, \mathrm{p}=0.5$ ). However, comparing the median number of otoliths per sample showed significant differences (Kruskal-Wallis test: $H=20.43$, df $=10, p=0.025)$. w5585 had a much greater number of otoliths in its enemas (Table 3 ), but when this seal was removed from the analysis there was no significant difference between individuals. Table 3 shows the species composition of the otoliths identified for each seal: $41 \%$ of enemas had evidence of fish consumption with the most common species identified being Protomyctophum choridon. Of the 2 seals with the highest number of otoliths in their enemas, w5585 with a short mean trip duration had a diet dominated by Lepidonoitothen larseni aggregation and Champsocephalus gunnari, whereas the myctophids P. choridon and Kreffichthys anderssoni dominated the diet of w1717, a seal that had a long mean trip duration.
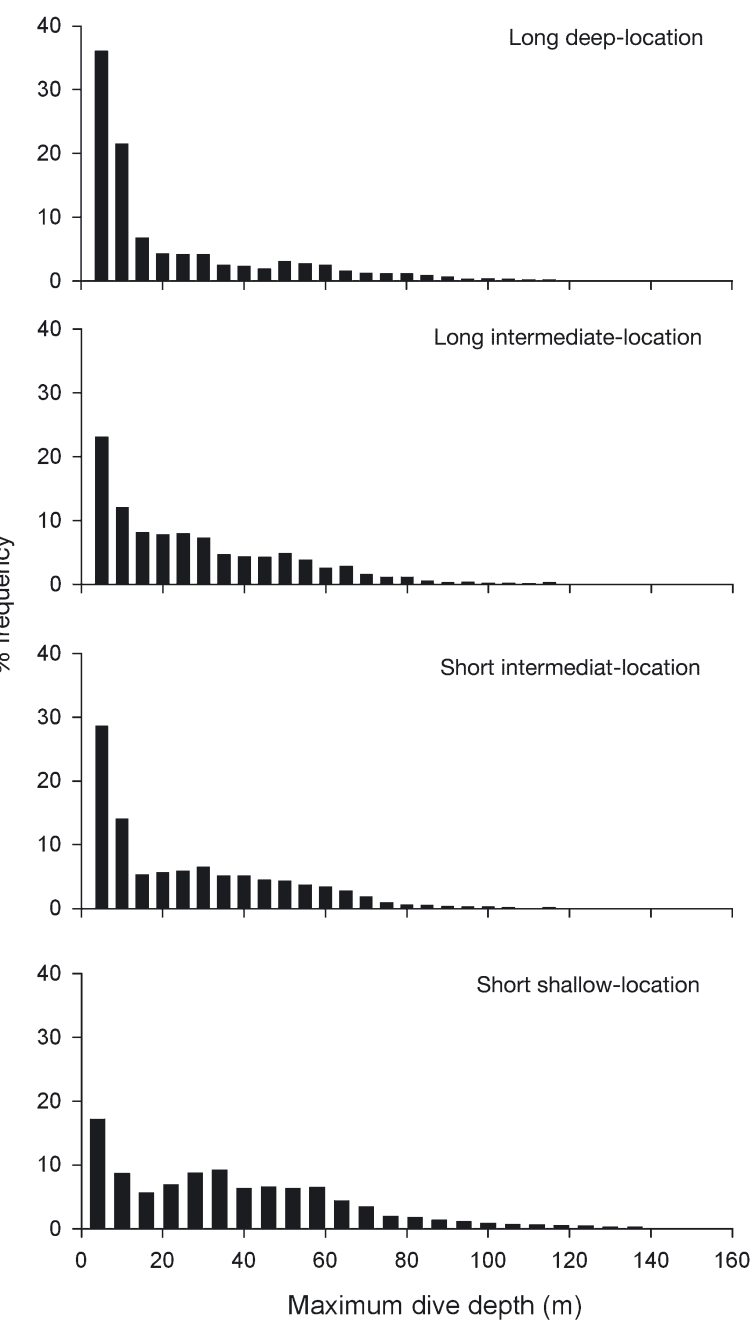

Fig. 4. Arctocephalus gazella. Percentage frequency distributions of dive depths in the 4 trip categories 

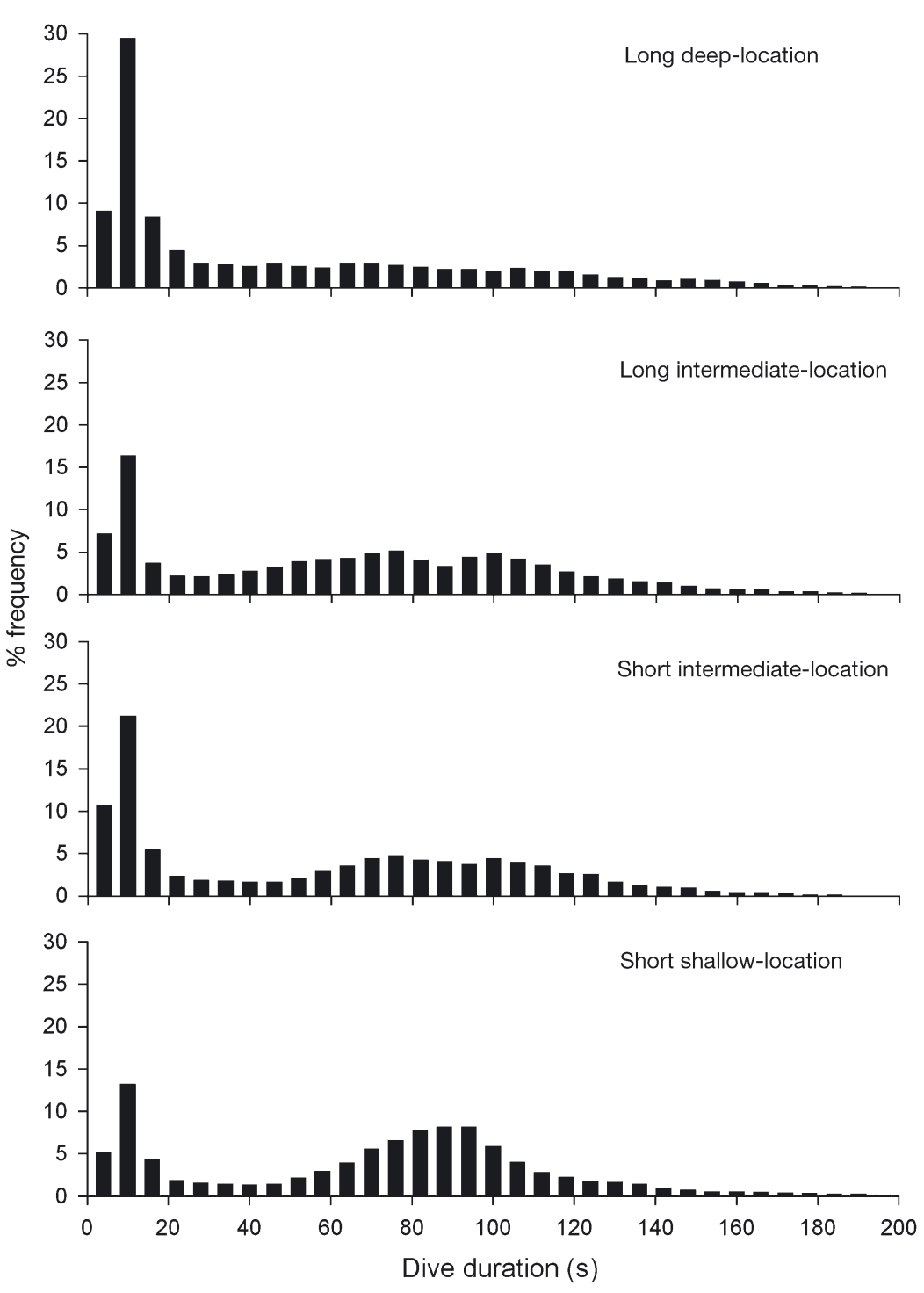

Fig. 5. Arctocephalus gazella. Percentage frequency distributions of dive durations in the 4 trip categories

\section{DISCUSSION}

We found significant differences in the foraging behaviour and locations of individual seals. However, our analysis also showed that the differences in foraging behaviour were most likely caused by differences in the foraging location. Therefore, the primary variable in the foraging success of female Antarctic fur seals is likely to be the decision about where to forage, rather than about how to forage in any particular circumstances. This suggests that the diving behaviour of these fur seals is likely to be narrowly constrained either by the distribution of prey in the water column in each region or by the distance over which the fur seals have to travel to each region.
Intra-specific variation

There were significant differences between individual seals in terms of both their foraging trip durations and the maximum distance they reached from the breeding beach. However, seals could not be separated into distinct groupings using either of these variables; most individuals undertook both near and far trips and overlapped in their at-sea distributions (Fig. 2). This is also shown by the positive correlation between the mean and the variance in the maximum distance travelled during a foraging trip.

Seals may gain an advantage by foraging repeatedly within the same area because, over a number of trips, they could build up knowledge of the prey distribution in that area. If a seal has previously encountered prey in an area it may be advantageous to return there if the patch was stable both spatially and temporally (although it should be noted that the PTT deployments in this study were non-consecutive). Bonadonna et al. (2001) found that fur seals foraging from Kerguelen tended to maintain direction and trip duration between consecutive trips, and suggested that this was to exploit subareas of previous feeding success. Hierarchical spatial structure of prey at South Georgia may influence the searching patterns used by fur seals (Murphy et al. 1988). Fauchald et al. (2000) suggested that experience is used to locate and travel to large-scale patches, in this case water masses, within which predators search for small-scale patches using shorter travel distances and higher turning frequencies. This has been proposed as a mechanism driving the observed temporal scales of foraging in fur seals, with bouts of dives interspersed with periods searching for prey patches at different scales (Boyd 1996).

The relationship between the age of seals and their mean trip duration suggests that older seals were exploiting the oceanic environment more often than younger seals. The youngest known age of a seal in this study was 9 yr. Considering that seals become sexually mature at 3 to 4 yr of age, this still represents an experienced individual. The exact breeding histories of these seals was unknown, but all successfully raised a pup to weaning during the season studied and all had been recorded with a pup in at least 1 previous year.

The mean trip duration appeared to have no effect on pup mass prior to weaning, and seals at the 
extremes of trip duration had pups of comparable mass. Although this result was based on a small sample size, it concurs with the findings of Arnould \& Boyd (1995) who showed that mothers could maintain the same overall delivery rate of energy to their pup irrespective of their trip duration.

There was no significant difference between individuals in the direction of travel from the colony. The correlation between increased mean direction and the variance suggests that, as the angles in this study were measured from the latitude of $54^{\circ} 00^{\prime} \mathrm{S}$, seals with a more northerly component to their foraging had an increased variability in their direction of travel, which may indicate a greater variability in the distribution of resources in this area. However all trips were restricted to a limited part of the potential foraging range, northwest of Bird Island (Fig. 2). This restricted foraging distribution has been shown in previous studies and may indicate an area where food resources are concentrated and relatively abundant (Boyd et al. 2002).

\section{Implications for foraging choices}

Staniland \& Boyd (2003) suggested that trip duration was a result of prey encounter rate on the outward journey. The fact that, in the present study, 2 individuals routinely undertook long-duration trips could suggest that trip duration, and hence distance, is predetermined in fur seals, i.e. individuals knew prior to leaving the breeding colony where they would forage and for how long. This seems unlikely, however, as on all trips, seals dived within shelf waters on their outward journey, indicating that they were attempting to forage. A number of factors could account for the indi-

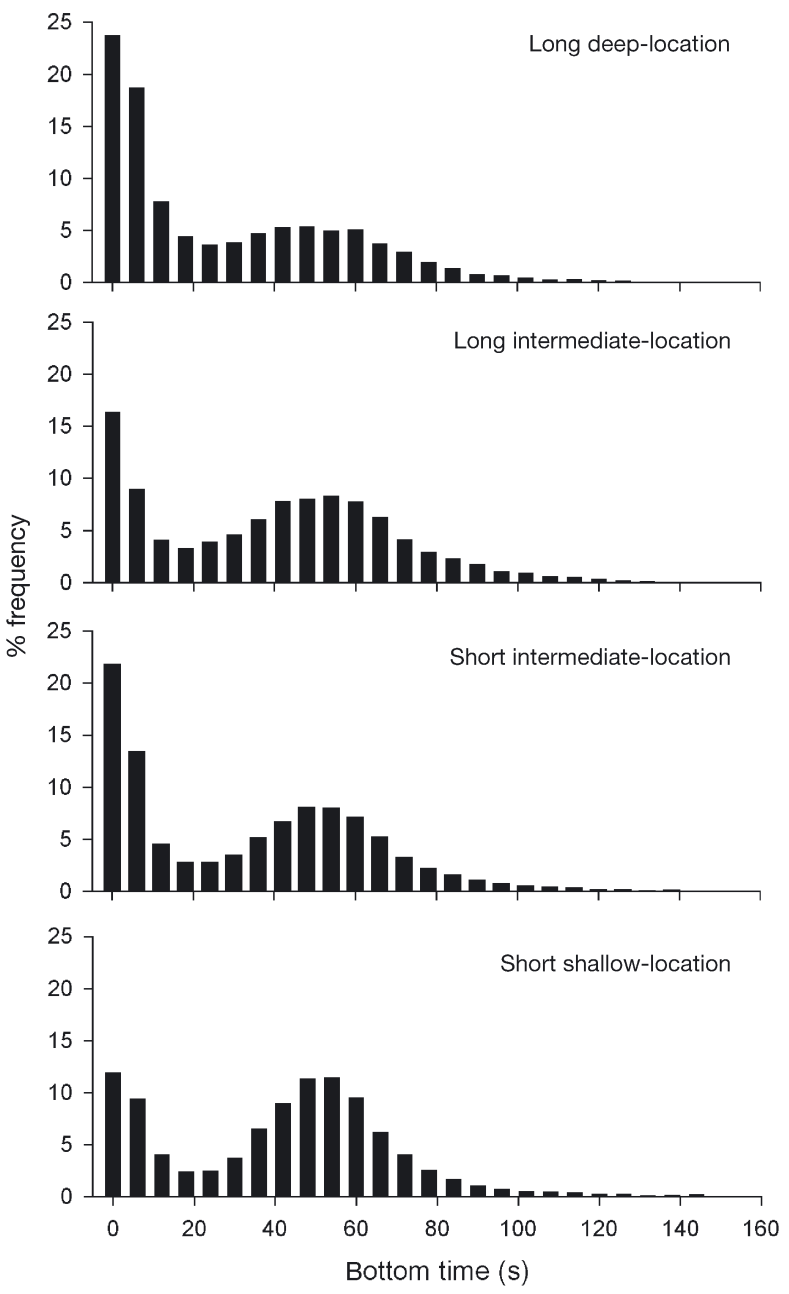

Fig. 6. Arctocephalus gazella. Percentage frequency distributions of dive bottom-times (i.e. time between end of descent and beginning of ascent in a dive) in the 4 trip categories

Table 3. Arctocephalus gazella. Diet data (enema contents). No.: number of enema; Krill length: back-calculated length of krill carapace remains; Unid. otoliths: total no. of unidentified otoliths; en: number of enemas containing identifiable otoliths; ot: total number of otoliths (including those that were too eroded to identify to species level)

\begin{tabular}{|c|c|c|c|c|c|c|c|c|c|c|c|c|c|c|c|}
\hline \multirow[t]{2}{*}{$\begin{array}{l}\text { Tag } \\
\text { no. }\end{array}$} & \multirow[t]{2}{*}{ No. } & \multirow{2}{*}{$\begin{array}{l}\text { Krill length } \\
(\mathrm{mm}) \\
\text { Mean (SD) }\end{array}$} & \multirow{2}{*}{$\begin{array}{c}\text { No. } \\
\text { with } \\
\text { fishes }\end{array}$} & \multicolumn{2}{|c|}{$\begin{array}{l}\text { Unid. } \\
\text { otoliths }\end{array}$} & \multicolumn{2}{|c|}{$\begin{array}{l}\text { Lepidonoitothen } \\
\text { larseni agg. }\end{array}$} & \multicolumn{2}{|c|}{$\begin{array}{c}\text { Champsocephalus } \\
\text { gunnari }\end{array}$} & \multicolumn{2}{|c|}{$\begin{array}{c}\text { Protomyctophum } \\
\text { choridon }\end{array}$} & \multicolumn{2}{|c|}{$\begin{array}{l}\text { Kreffichthys } \\
\text { anderssoni }\end{array}$} & \multicolumn{2}{|c|}{$\begin{array}{c}\text { Other } \\
\text { Myctophidae }\end{array}$} \\
\hline & & & & & & en & ot & en & ot & en & ot & en & ot & en & ot \\
\hline w1717 & 12 & $49.1(1.2)$ & 4 & 34 & & 1 & 1 & & & 2 & 26 & 2 & 7 & & \\
\hline w1753 & 11 & $49.4(1.6)$ & 3 & 4 & & 1 & 2 & 1 & 2 & & & & & & \\
\hline w2301 & 10 & $49.7(2.6)$ & 3 & 5 & & & & & & 1 & 4 & 1 & 1 & & \\
\hline w2317 & 9 & $49.6(1.7)$ & 6 & 11 & & & & 1 & 2 & 2 & 5 & & & 3 & 4 \\
\hline w2363 & 13 & $47.0(8.0)$ & 5 & 2 & & & & 1 & 1 & & & & & 1 & 1 \\
\hline w3913 & 16 & $49.0(1.2)$ & 5 & 8 & & & & & & 1 & 7 & & & 1 & 1 \\
\hline w5341 & 12 & $49.2(2.0)$ & 3 & 3 & 1 & & & 1 & 1 & 1 & 1 & & & & \\
\hline w5342 & 12 & $48.8(0.4)$ & 4 & 18 & 3 & & & 1 & 1 & 1 & 10 & 1 & 3 & 1 & 1 \\
\hline w5511 & 13 & $48.7(0.9)$ & 7 & 6 & 4 & & & 1 & 1 & 1 & 1 & & & & \\
\hline w5585 & 14 & 49.1 (1.9) & 9 & 63 & 5 & 3 & 25 & 7 & 27 & 2 & 2 & 1 & 2 & 2 & 2 \\
\hline w5753 & 12 & $48.2(1.3)$ & 6 & 4 & & 1 & 1 & 2 & 3 & & & & & & \\
\hline Total & 134 & & 55 & 158 & 13 & & 29 & & 38 & & 56 & & 13 & & 9 \\
\hline
\end{tabular}


vidual variation in trip distance and duration. Experience has been shown to be important in influencing foraging in bees (Pernal \& Currie 2001), birds (Cuthill et al. 1994, Kohlmann \& Risenhoover 1998) and fishes (Wildhaber \& Crowder 1991). Alternatively, competitive exclusion may force less competitive individuals to use another foraging area farther away. However, there appears to be no difference in the pay-off from long-distance as opposed to short-distance foraging, and both strategies are equally viable.

\section{Foraging location}

The 2 variables used to cluster trips, maximum distance reached and mean water depth of water where dives took place, provided 4 categories that were welldefined spatially. The separation of these categories appeared to be a function of the region associated with the edge of the continental shelf region and its associated water masses (Fig. 3). The oceanography of the South Georgia region shows strong inter-annual variation, although typically there are 2 water masses associated with the area northwest of Bird Island, where these seals were foraging: South Georgia Shelf Water (SGSW) is generally found close to the island and is mostly constrained to water depths of less than $500 \mathrm{~m}$; the other water mass, termed Antarctic Zone Water (AZW), extends beyond the $1500 \mathrm{~m}$ isobath (Fig. 3). In the year of this study the SGZW was predominately warmer and had a higher krill biomass than the AZW (Trathan et al. 2003). Between the 2 water masses there is a frontal region, associated with upwelling. Short shallow-location trips were confined to South Georgia Shelf Water whereas short intermediate-location trips were concentrated in the frontal zone. Long intermediate-location trips had a strong westerly component to their direction of travel compared to long deep-location trips, resulting in the fur seals remaining longer in shallower shelf waters.

Unlike some phocid species, fur seals travel at the surface and their dives are considered to be restricted to foraging events (Boyd 1996). Therefore, diving parameters such as time spent submerged, number of dives and dive rate can be used as indicators of foraging effort.

Antarctic fur seals at Macquarie Island have shown a strong correlation between their foraging trip durations and the number of dives undertaken (Robinson et al. 2002). The study of Robinson et al. (2002) suggested that these seals are operating in a homogenous ecosystem in terms of prey distribution and abundance. However in the current study neither trip category nor individual seal accounted for a significant amount of the variation in the total number of dives undertaken on a trip. This was in agreement with previous studies in South Georgia that have either shown no correlation between trip duration and the total number of dives, or a higher dive rate on short-duration trips (Arnould et al. 1996, Staniland \& Boyd 2003). Although seals on more distant trips spent much longer at sea, they also spent a much greater time travelling. This allocation of trip time to travelling is reflected in the strong significant differences between the 2 long and the 2 short trip-categories in terms of percentage time spent diving and dive rate. In all diving variables for which a significant effect of our model was found, trip category accounted for a larger proportion of the variation than individual seal. Individual seal was only a significant factor in dive rate and percentage time spent diving, both of which were strongly correlated with maximum distance travelled because of the known linear relationship between trip duration and distance (Staniland $\&$ Boyd 2003). We have already shown the strong influence of individual seal on trip distance, so it is not surprising that these time-dependent factors were also significant. The means of dive depth, dive duration and bottom time between 2 of the trip categories showed that the extremes of the trip categories (long deeplocation trips and short shallow-location trip) were significantly different. On average, seals on short-duration trips to shallow waters dived deeper and for longer than those on long-duration trips to deep waters. They also had longer bottom times on these dives. Goebel et al. (2000) found that Antarctic fur seals foraging in shelf waters around Cape Shirreff, Livingston Island $\left(62^{\circ} 29^{\prime} \mathrm{S}, 60^{\circ} 47^{\prime} \mathrm{W}\right)$, dived deeper and for longer than those foraging in deeper oceanic water. They suggested that differences in dive patterns might reflect exploitation of different prey resources in the different areas. Differences in diving behaviour of the New Zealand fur seal Arctocephalus forsteri between seasons and years reflected changes in their diet (Harcourt et al. 2002) and foraging tactics of harbour seals differed depending on the behaviour of their prey, both within and between prey species (Bowen et al. 2002). Staniland \& Boyd (2003), studying the same population of fur seals as in our study but in the preceding season, found similar differences in the diving behaviour, with seals in shallow shelf waters diving deeper, on average, than seals foraging in oceanic waters. This may suggest either that in this region there are differences between shelf and oceanic waters in the distribution or behaviour of the fur seals' main prey species, krill, or that seals are targeting different prey in different areas, e.g. different fish species. The dive depths of Antarctic fur seals at South Georgia have been shown to mirror the vertical movements of krill, their main prey (Croxall et al. 1985). However, krill movements are known to vary between 
different areas, seasons and environmental conditions (Godlewska 1996). Unfortunately little is known about the specific vertical migrations of the fish species exploited by fur seals in this region.

\section{Diet}

The data on diet showed no difference in the mean length of krill taken by individual seals. The incidence of fishes also showed no significant difference, though there was a difference in the median number of otoliths per sample. This difference was mostly attributable to Seal w5585, which had a greater total number of otoliths. Seal w1717 also had a large number of otoliths, but these were from a few individual scats and hence its median value was low.

Staniland et al. (unpubl.), studying geographical differences in the diet of female fur seals at the same breeding beach, also found no difference in the sizes of krill taken in shelf and oceanic waters. Based on a larger sample size of foraging trips, Staniland et al. (unpubl.) found significant differences in the incidence and the species composition of fishes. We might therefore expect that seals concentrating their foraging within these 2 different areas would show similar differences in their diets. There was some indication of a difference in the species composition of 2 of the individuals at the extremes of both trip duration and maximum distance. w5585, which appeared to forage almost exclusively in shelf waters, had large numbers of Lepidonoitothen larseni and Champsocephalus gunnari, 2 characteristic shallow-water species (Gon \& Heemstra 1990, Kock \& Everson 1997). The fish species dominating the diet of w1717, that appeared to forage mostly in water $>1000 \mathrm{~m}$, were the myctophids Protomyctophum choridon and Kreffichthys anderssoni which, according to ship-based sampling, are generally found in these deeper waters (Gon \& Heemstra 1990).

\section{CONCLUSIONS}

We have shown in this study that there are strong differences between the foraging behaviour of individual seals. While some individuals concentrate their foraging in distant oceanic waters, other seals forage in shelf waters closer to the breeding colony. However, foraging location is the main factor determining a seal's diving behaviour, rather than individual variation. Although there was some evidence of a difference in the fish species composition, there were no significant differences between individual seals in terms of the incidence of fishes in the diet or the size of krill eaten. It would therefore appear that although individual seals could be exploiting areas of previous feeding success, their diving behaviour is determined by the spatial and temporal distribution of the prey within these areas.

Acknowledgements. The authors thank all the staff at the Bird Island research station for their help in the field. We also thank P. Trathan and the 4 anonymous referees for their helpful comments on earlier versions of this manuscript. The work is part of the DYNAMOE science program within the British Antarctic Survey and NERC.

\section{LITERATURE CITED}

Arnould JPY, Boyd IL (1995) Temporal patterns of milkproduction in Antarctic fur seals (Arctocephalus gazella). J Zool 237:1-12

Arnould JPY, Boyd IL, Speakman JR (1996) The relationship between foraging behaviour and energy expenditure in Antarctic fur seals. J Zool 239:769-782

Batschelet E (1981) Circular statistics in biology. Academic Press, New York

Bence JR (1986) Feeding rate and attack specialization - the roles of predator experience and energetic tradeoffs. Environ Biol Fish 16:113-121

Bonadonna F, Lea MA, Dehorter O, Guinet C (2001) Foraging ground fidelity and route-choice tactics of a marine predator: the Antarctic fur seal Arctocephalus gazella. Mar Ecol Prog Ser 223:287-297

Bowen WD, Tully D, Boness DJ, Bulheier BM, Marshall GJ (2002) Prey-dependent foraging tactics and prey profitability in a marine mammal. Mar Ecol Prog Ser 244:235-245

Boyd IL (1996) Temporal scales of foraging in a marine predator. Ecology 77:426-434

Boyd IL (1999) Foraging and provisioning in Antarctic fur seals: interannual variability in time-energy budgets. Behav Ecol 10:198-208

Boyd IL, Reid K, Bevan R (1995) Swimming speed and allocation of time during the dive cycle in Antarctic fur seals. Anim Behav 50:769-784

Boyd IL, McCafferty DJ, Walker TR (1997) Variation in foraging effort by lactating Antarctic fur seals: response to simulated increased foraging cost. Behav Ecol Sociobiol 40:135-144

Boyd IL, McCafferty DJ, Reid K, Taylor R, Walker TR (1998) Dispersal of male and female Antarctic fur seals Arctocephalus gazella. Can J Fish Aquat Sci 55:845-852

Boyd IL, Staniland IJ, Martin AR (2002) Distribution of foraging by female Antarctic fur seals. Mar Ecol Prog Ser 242: 285-294

Brandon MA, Murphy EJ, Trathan PN, Bone DG (2000) Physical oceanographic conditions to the northwest of the subAntarctic island of South Georgia. J Geophys Res C 105: $23983-23996$

Croxall JP, Everson I, Kooyman GL, Ricketts C, Davis RW (1985) Fur seal diving behaviour in relation to vertical distribution of krill. J Anim Ecol 54:1-8

Cuthill IC, Haccou P, Kacelnik A (1994) Starlings (Sturnus vulgaris) exploiting patches - response to long-term changes in travel-time. Behav Ecol 5:81-90

Fauchald P, Erikstad KE, Skarsfjord H (2000) Scale-dependent predator-prey interactions: the hierarchical spatial distribution of seabirds and prey. Ecology 81:773-783

Fedriani JM, Kohn MH (2001) Genotyping faeces links individuals to their diet. Ecol Lett 4:477-483 
Godlewska M (1996) Vertical migrations of krill (Euphausia superba Dana). Pol Arch Hydrob 43:9-63

Goebel ME, Costa DP, Crocker DE, Sterling JT, Demer DA (2000) Foraging ranges and dive patterns in relation to bathymetry and time-of-day of Antarctic fur seals, Cape Shirreff, Livingston Island, Antarctica. In: Davidson W, Howard-Williams C, Broady P (eds) Antarctic ecosystems: models for wider ecological understanding. Caxton Press, Christchurch, p 47-50

Gon O, Heemstra PC (1990) Fishes of the Southern Ocean, Vol 1. JLB Smith Institute, Grahamstown, South Africa

Gosscustard JD, Sutherland WJ (1984) Feeding specializations in oystercatchers Haematopus ostralegus. Anim Behav 32:299-301

Harcourt RG, Bradshaw CJA, Dickson K, Davis LS (2002) Foraging ecology of a generalist predator, the female New Zealand fur seal. Mar Ecol Prog Ser 227:11-24

Heithaus MR, Dill LM, Marshall GJ, Buhleier B (2002) Habitat use and foraging behavior of tiger sharks (Galeocerdo cavier) in a seagrass ecosystem. Mar Biol 140:237-248

Holbrook SJ, Schmitt RJ (1992) Causes and consequences of dietary specialization in surfperches - patch choice and intraspecific competition. Ecology 73:402-412

Kock KH, Everson I (1997) Biology and ecology of mackerel icefish, Champsocephalus gunnari: an Antarctic fish lacking hemoglobin. Comp Biochem Physiol A 118:1067-1077

Kohlmann SG, Risenhoover KL (1998) Effects of resource distribution, patch spacing, and preharvest information on foraging decisions of northern bobwhites. Behav Ecol 9: $177-186$

Lomnicki A (1980) Regulation of population density due to individual differences and patchy environment. Oikos 35: 185-193

Lomnicki A (1988) Population ecology of individuals. Princeton University Press, Princeton, NJ

McCafferty DJ, Boyd IL, Walker TR, Taylor RI (1998) Foraging responses of Antarctic fur seals to changes in the marine environment. Mar Ecol Prog Ser 166:285-299

Milinski M (1982) Optimal foraging-the influence of intraspecific competition on diet selection. Behav Ecol Sociobiol 11:109-115

Murphy EJ, Morris DJ, Watkins JL, Priddle J (1988) Scales of interaction between Antarctic krill and the environment.

Editorial responsibility: Otto Kinne (Editor), Oldendorf/Luhe, Germany
In: Sahrhage D (ed) Antarctic Ocean and resources variability. Springer-Verlag, Berlin, p 120-130

Pernal SF, Currie RW (2001) The influence of pollen quality on foraging behavior in honeybees (Apis mellifera L.). Behav Ecol Sociobiol 51:53-68

Reid K (1995) The diet of Antarctic fur seals Arctocephalus gazella Peters 1875 during winter at South Georgia. Antarct Sci 7:241-249

Reid K (1996) A guide to the use of otoliths in the study of predators at South Georgia. British Antarctic Survey, Cambridge

Reid K, Measures J (1998) Determining the sex of Antarctic krill Euphausia superba using carapace measurements. Polar Biol 19:145-147

Robinson SA, Goldsworthy SG, van den Hoff J, Hindell MA (2002) The foraging ecology of two sympatric fur seal species, Arctocephalus gazella and Arctocephalus tropicalis, at Macquarie Island during the austral summer. Mar Freshw Res 53:1071-1082

Sokal RR, Rohlf FJ (1995) Biometry: the principles and practice of statistics in biological research, 3rd edn. WH Freeman, New York

Staniland IJ, Boyd IL (2003) Variation in the foraging location of Antarctic fur seals (Arctocephalus gazella), the effects on diving behaviour. Mar Mamm Sci 19:331-343

Staniland IJ, Taylor RI, Boyd IL (2003) An enema method for obtainig fecal material from known individual seals on land. Mar Mamm Sci 19:363-370

Sutherland WJ (1997) From individual behaviour to population ecology. Oxford University Press, Oxford

Trathan PN, Brierley AS, Brandon MA, Bone DG, Goss C, Grant SA, Murphy EJ, Watkins J (2003) Oceanographic variability and changes in Antarctic krill (Euphausia superba) abundance at South Georgia. Fish Oceanogr 12(6):569-583

Werner EE, Gilliam JF (1984) The ontogenetic niche and species interactions in size structured populations. Annu Rev Ecol Syst 15:393-425

Whitfield DP (1990) Individual feeding specializations of wintering turnstone Arenaria interpres. J Anim Ecol 59:193-211

Wildhaber ML, Crowder LB (1991) Mechanisms of patch choice by bluegills (Lepomis macrochirus) foraging in a variable environment. Copeia 1991:445-460

Submitted: March 11, 2003; Accepted: February 17, 2004 Proofs received from author(s): June 16, 2004 